\title{
The role of family processes in depressive symptom recovery during the transition to adolescence
}

\author{
Katharine Ann Buck* \\ Department of Human Development and Family Studies, University of Saint Joseph, West Hartford, CT 06117, USA
}

\begin{abstract}
Despite common increases in depressive symptoms that occur from childhood to adolescence, recent trajectory research has identified a distinct group of children whose depressive symptoms decline during this transition. Using data from 956 adolescents ages 11 to 15 who participated in the NICHD Study of Early Child Care and Youth Development, this study examined four family factors thought to play a role in depressive symptom recovery: a two-parent household, interparental intimacy, the parent-child relationship, and parental depression. Two classes of trajectories were identified, which suggests that there is heterogeneity in depressive symptoms as children transition into adolescence. Males were more likely to be in the declining class. A two-parent household, low parental depression, and a positive mother-child relationship were associated with declining depressive symptoms for both males and females across development. Results also demonstrated that the mother-child relationship and paternal depression mediated the association of interparental intimacy and declining depressive symptoms.
\end{abstract}

\section{Introduction}

Depression is the most common mental health disorder of adolescence, placing youth at risk for suicide, academic failure, substance abuse, and troubled relationships [1]. Despite common increases in depressive symptoms that occur from childhood to adolescence, recent trajectory research has identified a distinct group of children whose depressive symptoms decline during this transition [2-7]. Depressive symptoms may improve without treatment, but why these improvements occur is largely unknown [8,9]. Using data from 956 adolescents ages 11 to 15 who participated in the NICHD Study of Early Child Care and Youth Development, the current study examined the role of four family factors - a two-parent household, interparental intimacy, the parent-child relationship, and parental depression - in predicting depressive symptom trajectories as children enter adolescence.

\section{Developmental Trajectories of Depressive Symptoms}

On average, depressive symptoms increase approximately threefold from late childhood to early adolescence [2]. However, this common developmental trend fails to capture the heterogeneity of depressive symptom trajectories [10,11]. Recent research in developmental psychopathology indicates that multiple developmental pathways may better characterise the nature of depressive symptoms across development [11]. To date, six studies have demonstrated that some children and adolescents with moderate to high depressive symptoms show improvement over time, without treatment. This trajectory research has found that declines in depressive symptoms occur across development: from early childhood through late adolescence (ages 4-18), late childhood to early adolescence (11-15), late adolescence (11-18), and early adulthood (ages 12-25), and from late adolescence to early adulthood (18-22) [4-6,10,12].

\section{The Role of Family in Adolescent Depressive Symptom Recovery}

As children approach adolescence, they encounter a number of developmental challenges that increase their risk for depressive symptoms. Examples include puberty, increased sensitivity to peer evaluations, and cognitive changes associated with imaginary audience and heightened social comparison [2]. Fortunately, a stable family structure and supportive family relationships may protect adolescents from the negative effects of these stressful experiences [1315]. The current study examines the role of family relationships (i.e. interparental intimacy, parent-child relationship) and one component of family structure - a two-parent household - in depressive symptom recovery as children transition into adolescence.

\section{Two-Parent Household and Children's Depressive Symptom Recovery}

The risks associated with single-parent households for children's adjustment have been well-documented [16,17]. Examples include poor school performance, delinquency, and psychological maladjustment $[18,19]$. Children in single-parent households are 4.7 times more likely to develop a mood disorder than those in two-parent households [20]. In 2011 there were over 14 million single-parent households in the United States, with $80 \%$ headed by single mothers [21]. Children

${ }^{\star}$ Correspondence to: Katharine Ann Buck, Department of Human Development and Family Studies, University of Saint Joseph, West Hartford, CT 06117, USA, Tel: 860-231-2014; E-mail: kbuck@usj.edu

Key words: depressive symptom recovery, adolescent depression, family processes, interparental intimacy, parental depression, paternal depression, parent-child relationship, mother-child relationship, depression trajectories

Received: June 12, 2018; Accepted: June 23, 2018; Published: June 27, 2018 
in two-parent households experience fewer adverse life events, are less likely to be living in poverty, and have greater perceived social support from friends and family [22,23]. Research on depression symptom trajectories has identified two-parent households as a protective factor against adolescent depression [10,20]. Costello and colleagues (2008) found that a two-parent household predicted membership in the "no depressed mood" group when compared with the "depressed mood" trajectory group. Although a two-parent household appears to protect against the onset of depressive symptoms, it is unclear whether it reduces children's existing symptoms as they enter adolescence. The support children may receive from having both parents at home may be particularly important for reducing depressive symptoms during the transition to adolescence, given the developmental events (e.g. puberty, sensitivity to peer evaluation) known to heighten vulnerability to depression and increase depressive symptoms. Thus, the first goal of the current study was to examine whether living in a two-parent household would be associated with declining depressive symptoms across development.

\section{Interparental Intimacy, Depressive Symptom Recovery, and Potential Mediators}

Family systems theory may shed light on family relationships that account for improvements in children's depressive symptoms as they enter adolescence. Family systems theorists underscore the interdependence of individuals within the family, such that the wellbeing of one family member is impacted by the functioning of multiple subsystems within the whole family unit $[24,25]$. The marital subsystem in particular has a salient impact on children's adjustment [26]. A wealth of research has documented the link between interparental conflict and children's internalizing problems [27-29]. Interparental conflict is thought to deplete the emotional resources necessary for parents to be involved, warm, and monitor their children's whereabouts [27,30,31]. Despite consistent evidence documenting the negative impact of interparental conflict on children, there is little research examining whether a positive interparental relationship contributes to naturally-occurring declines in children's depressive symptoms. The absence of parental conflict does not ensure positive child adjustment, but high interparental intimacy may create an emotional climate within the family system that supports the child's mental health and reduces depressive symptoms during the transition to adolescence. In families characterised by a positive emotional climate, adolescents seek out parental support in discussing problems with peers and evaluate parental guidance as helpful [32]. Thus, the second goal of the current study was to examine whether interparental intimacy - a partner's feelings of being understood, supported, and cared for - is associated with children's depressive symptom recovery.

Why would interparental intimacy reduce children's depressive symptoms? The spillover hypothesis may help to explain two potential mechanisms - a positive parent-child relationship and low parental depression. The spillover hypothesis has been used to describe the effect of the parents' romantic relationship on parent-child interactions [33]. To date, research has focused on the negative spillover that occurs when marital conflict impairs parenting or the parent-child relationship. The spillover hypothesis may be applied more broadly using a resilience lens in examining whether interparental intimacy promotes a positive parent-child relationship. Previous research has demonstrated that interparental intimacy is associated with fathers' positive perceptions of their infant and sensitivity with their 3-year-olds [34]. This suggests that interparental intimacy may promote a positive parent-child relationship in early childhood, but whether the effect is maintained during adolescence is unknown. Researchers have found an association between positive parent-child relationships and low depression during adolescence; Costello et al. (2008) demonstrated that adolescents who reported feeling supported by their parents were more likely to be in the "not depressed group" than in the "stable low" or "early, high declining" depression trajectory groups. Thus, drawing on existing literature, it is hypothesized that a positive parent-child relationship will mediate the association between interparental intimacy and declines in children's depressive symptoms across development.

The spillover hypothesis also may explain a second mechanism by which interparental intimacy may promote depressive symptom recovery in children - low parental depression [35]. Poor marital quality predicts high levels of parental depression [36,37]. The negative effects of parental depression on children's depressive symptoms have been well-documented [38,39]. Parental depression may interfere with parents' ability to assess children's behaviour and respond in an emotionally appropriate manner [38]. Fortunately, when parents feel supported by one another, their own depressive symptoms may be lessened [40]. Taraban and colleagues [35] have argued that such support allows parents to maintain "routine and regularity in the household," which may be reflective of a family climate that supports children in their transition to adolescence. One study found that low maternal depression predicted low depressive symptoms in adolescents ages 11-15 [4]. Thus, building on extant research, it is hypothesized that low parental depression would mediate the association between interparental intimacy and declining depressive symptoms in children.

\section{Overview of the Current Study}

The current study contributes to the existing literature by examining family processes that may account for declines in depressive symptoms that occur for some children as they transition into adolescence. This study also builds on previous research by examining both mothers' and fathers' depressive symptoms and each parent's relationship with their child. Data come from the national sample of the NICHD Study of Early Child Care and Youth Development when children were in grade 5, grade 6 , and at age 15 . The first hypothesis of the current study was that children living in a two-parent household would experience declining depressive symptoms across development. Hypothesis two was that interparental intimacy would be associated with a reduction in children's depressive symptoms during the transition to adolescence. Hypothesis three and four were that (3) a positive parent-child relationship and (4) low parental depression would mediate the association between interparental intimacy and declines in children's depressive symptoms during this transition. Given that rates of depression differ for males and females, gender was examined as a class distinguisher to determine whether the effects of these family processes differed across gender.

\section{Methods}

\section{Participants}

Participants were 956 adolescents from the NICHD Study of Early Child Care and Youth Development (86.9\% White; $4.0 \%$ Black; 4.5\% Hispanic; $2.9 \%$ Asian; and $1.7 \%$ other). Data were drawn from grade 5, grade 6 , and at age 15 . Participants were recruited from 10 sites across the United States. Although diverse, the NICHD sample is somewhat more advantaged than the general U.S. population. The majority of parents had a four-year degree (53.3\%), and average income was approximately $\$ 80,000$. Mothers who had severe mental illness or significant birth complications were excluded. 


\section{Measures}

Two-parent household: This categorical variable indicated whether the child's biological or adoptive father lived full-time within the household when the child was in fifth grade $(0=$ no father in household; 1 = father in household). The majority of fathers lived in the home (67.21\%).

Interparental intimacy: Interparental intimacy was assessed with mother's report on the "Love and Relationships" questionnaire, which is the six-item emotional intimacy subscale of the Personal Assessment of Intimacy in Relationships (PAIR) [41]. Items ranged from 1 ("strongly disagree") to 5 ("strongly agree"), with higher scores indicating greater interparental intimacy. Sample items included, "My spouse/partner listens to me when I need someone to talk to," and "I can state my feelings without him getting defensive." Internal reliability was 89 (Cronbach's $\alpha$ ).

Parent-child relationship: Mothers and fathers reported on their relationship with the child on the 30-item, "Child-Parent Relationship Scale," which was adapted from the Student-Teacher Relationship Scale (STRS) [42]. Sample items included, "If upset, my child seeks comfort from me," and "My child values his/her relationship with me." Items ranged from 1 ("definitely does not apply") to 5 ("definitely applies"). Scores ranged from 15 to 75 with higher scores indicating a better relationship between the parent and the child. Reliability was .82 for mothers and .83 for fathers (Cronbach's $\alpha$ ).

Parental depression: Mothers and fathers reported their depressive symptoms on the Center for Epidemiological Studies Depression Scale (CES-D) when their children were in $5^{\text {th }}$ grade [43]. This measure consisted of 20 items on a 4-point scale. Responses characterised how they felt during the past week with items ranging from 0 ("rarely or none of the time; less than once a week") to 3 ("most or all of the time; 5-7 days a week") and were summed for a total depressive symptoms score (Cronbach's $\alpha=.90$ for mothers, .87 for fathers). Possible scores range from 0 to 60 . Actual scores ranged from 0 to 49 for mothers and 0 to 47 for fathers, with higher scores indicating higher levels of depressive symptoms. Sample items included, "I was bothered by things that usually don't bother me," and "I felt depressed."

Child depressive symptoms: Children reported their depressive symptoms on the short form of the Children's Depression Inventory (CDI) [44] in $5^{\text {th }}$ and $6^{\text {th }}$ grades, and at age 15 . This 10 -item questionnaire assessed the child's symptoms over the past two weeks. Ten sets of three statements were presented, and children selected the one that best described how they felt, with scores above 8 for girls and 10 for boys indicating "well above average." Items inquired about dysphoric mood, lack of pleasure, and low self-esteem. Responses ranged from 0 (normative behaviour) to 2 (depressive symptoms) and were summed for a total depressive symptoms score. Possible scores ranged from 0 to 20 (actual scores at grade $5=0-15$, at grade $6=0-19$, at age $15=0-18$ ). Internal consistency was .80 (Cronbach's $\alpha$ ) and correlated .89 with the long form of the CDI.

\section{Results}

\section{Identifying Depression Symptom Trajectories}

All analyses were conducted using Mplus [45]. Maternal employment, child ethnicity, and income-to-needs ratio were included in each model as control variables. First, a basic linear growth model was examined such that depressive symptoms were estimated for the entire sample to follow straight-line, linear growth. Second, two- and three- class models of latent trajectories of depression symptoms at $5^{\text {th }}$ grade, $6^{\text {th }}$ grade, and at age 15 were examined using general growth mixture modeling (GGMM). The fit statistics of the basic linear growth model were compared to the two- and three-class models. The Lo, Mendell, \& Rubin (2001) [46] procedure indicated significant improvement in model fit for a two-class versus one-class model $(\mathrm{p}=.00001)$. Nagin (1999) [47] suggested that a model with the lowest Bayesian Information Criterion (BIC) should be chosen. A BIC score that differs more than three is "strong evidence," and more than five is "very strong evidence," for two models to differ (Raftery, 1995) [48]. The BIC fit index indicated that the three class model was not significantly better than the two class model. Thus, the BIC fit index led to the selection of the two-class model (see Table 1). The class with declining depressive symptoms consisted of $43.9 \%$ of the sample. Males were more likely to be in the declining class. Missing data were dealt with by Full Information Maximum Likelihood (FIML), which uses all available data to estimate models.

\section{Predictors of Latent Class Membership}

Class distinguishers: Logistic regression analysis was conducted to examine whether a two-parent household, interparental intimacy, mother-child/father-child relationship, and maternal/paternal depression predicted class membership. Correlations among predictor variables are shown in Table 2. Results from the regression analysis are shown in Table 3. After child ethnicity, income-to-needs ratio, and maternal employment were controlled, a two-parent household, paternal depression, and the mother-child relationship significantly

Table 1. Models of Depressive Symptom Trajectories

\begin{tabular}{|c|c|c|c|}
\hline & BIC & Entropy & VLMR \\
\hline 1-class & 12812.83 & $\mathrm{n} / \mathrm{a}$ & $\mathrm{n} / \mathrm{a}$ \\
\hline 2-class & 11146.02 & .80 & $.00001^{* *}$ \\
\hline 3-class & 11613.98 & .77 & $.01^{*}$ \\
\hline
\end{tabular}

Note: Residual variances were freed across class and time. $*=p \leq .05 ; * *=p \leq .01$. VLMR $=$ Vuong-Lo-Mendell-Rubin likelihood (2001) procedure indicated that a three-class solution could suffice, but one class contained only $6 \%$ of the sample.

Table 2. Correlations among Predictor Variables

\begin{tabular}{|c|c|c|c|c|c|c|}
\hline & int & f-c rel & m-c rel & pdep & mdep & twop \\
\hline int & -- & $.20^{* *}$ & $.28^{* *}$ & $-.24^{* *}$ & $-.43^{* *}$ & .01 \\
\hline f-c rel & & -- & $.45^{* *}$ & $-.37^{* *}$ & $-.11^{* *}$ & $.21^{* *}$ \\
\hline m-c rel & & & -- & $-.19^{* *}$ & $-.30^{* *}$ & $.07^{*}$ \\
\hline pdep & & & & -- & $.18^{* *}$ & $-.11^{* *}$ \\
\hline mdep & & & & & -- & $-.20^{* *}$ \\
\hline twop & & & & & & -- \\
\hline
\end{tabular}

Note: "int" = interparental intimacy, "f-c rel" "m-c rel" = father-child and mother-child relationship, respectively, "pdep" "mdep" = paternal and maternal depression, respectively, "twop" = two parent household.

*Significantly different than zero at $p<.05, * *$ significantly different than zero at $p<.01$

Table 3. Predictors of Declining Depressive Symptoms from Childhood to Early Adolescence

\begin{tabular}{|l|c|c|c|}
\hline \multicolumn{1}{|c|}{} & $\boldsymbol{\beta}$ & $\boldsymbol{S D}$ & $\boldsymbol{p}$ \\
\hline Maternal depression & -.01 & .06 & .84 \\
\hline Paternal depression & -.18 & .07 & $.007^{* *}$ \\
\hline Mother-child relationship & .15 & .06 & $.01^{* *}$ \\
\hline Father-child relationship & -.06 & .06 & 30 \\
\hline Two-parent household & .13 & .06 & $.01^{* *}$ \\
\hline Interparental intimacy & .07 & .06 & .25 \\
\hline Maternal employment & .04 & .05 & .43 \\
\hline Child ethnicity & .02 & .05 & .22 \\
\hline Income to needs ratio & .02 & .05 & .67 \\
\hline
\end{tabular}

Note: $* *=p \leq .01$. Estimates represent standardised coefficients. Estimates represent final regression analysis with all predictors in one model. 
predicted class membership. That is, children living in a two-parent household, those with fathers who had low levels of depression, and those who had a positive relationship with their mothers were more likely to be in the declining depressive symptom class. Predictors did not differ between males and females.

Mediational models: To determine whether interparental intimacy was indirectly related to children's depressive trajectories via the parentchild relationship or parental depression, two mediation models were examined. Tests of indirect effects, were specified with the command, MODEL INDIRECT, in Mplus. The first mediation model examined whether the mother-child and father-child relationship mediated the association between interparental intimacy and children's declining depressive symptoms. Results demonstrated that the mother-child relationship, but not the father-child relationship, mediated the association (Figure 1; path coefficient $=.03, \mathrm{p}=.02$ ). Fit statistics for the model were strong $(\mathrm{CFI}=.95, \mathrm{TLI}=.86, \mathrm{RMSEA}=.04)$. The second mediation model examined whether maternal and paternal depression mediated the relation between interparental intimacy and children's declining depressive symptoms (Figure 2). Results demonstrated that interparental intimacy was associated with children's depressive symptom trajectories indirectly via paternal depression, but not maternal depression (path coefficient $=.03, \mathrm{p}=.009$ ). Fit statistics were strong $(\mathrm{CFI}=.94, \mathrm{TLI}=.87$, RMSEA $=.06)$.

\section{Discussion}

Overview of Findings: The current study contributes to the existing literature by identifying a variety of family factors that appear to play a role in depression symptom recovery for some children as they transition into adolescence. The two-class model of increasing and decreasing depressive symptoms is in line with previous literature that suggests there is heterogeneity in depressive symptoms across development $[5,6,10,11,12$,]. Males were more likely to be in the decreasing class. This follows prior research indicating that females show higher levels and steeper increases in depressive symptoms across late childhood and early adolescence [4]. The following family processes were associated directly with children's declining depressive symptoms: a two-parent household, low paternal depression, and a positive motherchild relationship. Interparental intimacy was associated indirectly with declines in depressive symptoms via the mother-child relationship and paternal depression. These predictors did not differ for males versus females.

Two-Parent Household and Depressive Symptom Recovery: Findings confirmed the first hypothesis that having a two-parent household would be associated with declining depressive symptoms across development. This association was significant even after controlling for income-to-needs ratio. Previous research has demonstrated that children in single-parent households are at an

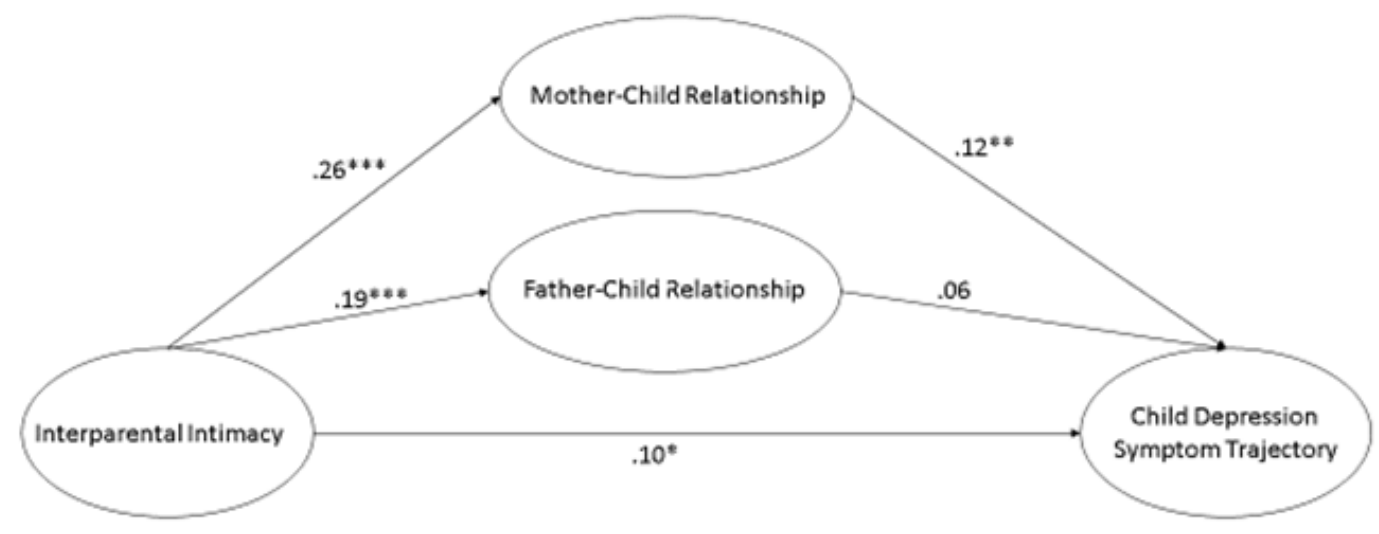

Figure 1. Mother-Child Relationship Mediating Interparental Intimacy and Child Depressive Symptom Trajectory

Note. ${ }^{*} \mathrm{p} \leq .05 ; * * \mathrm{p} \leq .01 ; * * * \mathrm{p} \leq .001$. Estimates represent standardised path coefficients.

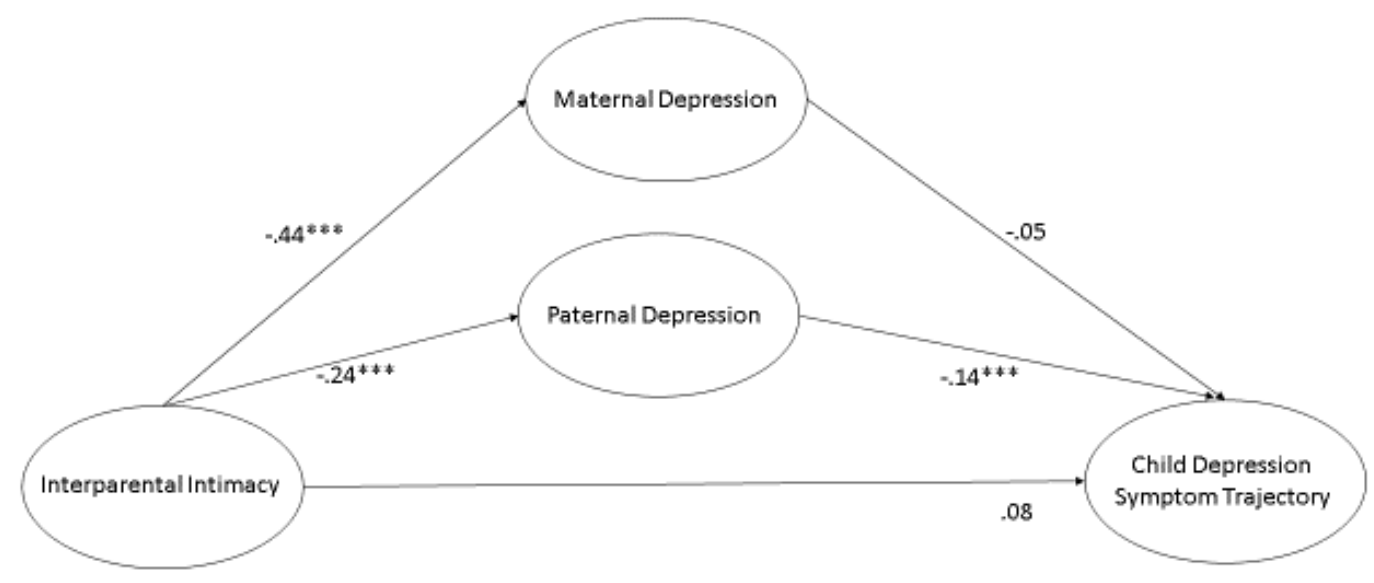

Figure 2. Paternal Depression Mediating Interparental Intimacy and Child Depressive Symptom Trajectory

Note. ${ }^{* *} \mathrm{p} \leq .01 ; * * \mathrm{p} \leq .001$. Estimates represent standardised path coefficients. 
increased risk of living in poverty, and in turn, experience internalizing symptoms [22]. That a two-parent household predicts declines in depressive symptoms over and above income level suggests that family dynamics associated with two-parent households aside from income may be critical in reducing children's depressive symptoms. When both parents are present, they are less likely to be stressed and more likely to have the emotional resources needed to co-parent responsively and attend to their child's emotional needs [20,49]. Dimensions of parenting quality (e.g. involvement, monitoring) not examined in the current study may be critical mechanisms in linking a two-parent household to children's depressive symptom recovery.

Interparental Intimacy and Depressive Symptom Recovery: The second hypothesis was that interparental intimacy would be associated with declining depressive symptoms. Findings did not confirm a direct association; however, interparental intimacy was indirectly associated with declines in depressive symptoms via a positive mother-child relationship and low paternal depression. Thus, partial support was found for hypotheses three and four - (3) that the mother-child and father-child relationship and (4) mother's and father's depression would mediate interparental intimacy and children's declining depressive symptoms. These findings contribute to previous literature that has focused on the negative impact of marital conflict on children's adjustment [50].

Results from the first mediation model suggest that when parents have high emotional intimacy, mothers are more likely to have a strong, positive relationship with their child, which may then reduce the child's depressive symptoms. Fredrickson's (2001) [51] broadenand-build theory of positive emotions offers a possible explanation for this association. In this theory, Fredrickson suggests that intimacy may "broaden and build people's momentary thought-action repertoires and build their enduring personal resources, ranging from physical and intellectual resources to social and psychological resources" [40]. Thus, mothers who feel supported in their marital relationship may be better equipped to establish a warm, supportive relationship with their child. This relationship may offer the child critical support during the difficult transition into adolescence, and thus reduce their depressive symptoms.

Given the key role that paternal depression appears to play in children's depression, it was surprising that the mother-child relationship, but not the father-child relationship, was a significant mediator. It is also noteworthy because previous research has demonstrated that the father-child relationship, not mother-child relationship, accounts for changes in severity of child mental health symptoms from ages 13 to 16 [50]. This discrepant finding may be due in part to measurement differences such that the current study used parents' report of the parent-child relationship, whereas Suh and colleagues (2016) used the child's report. Future research should continue to explore the relative role of the mother-child and father-child relationship in predicting children's depressive symptoms across time.

Results from the second mediation model suggest that when parents' emotional intimacy is high, fathers are less depressed, which then appears to reduce children's depressive symptoms. The association between low paternal depression and declining child depressive symptoms may reflect fathers' increased ability to set limits, negotiate conflict, and show interest in the child's life [52]. These skills are particularly important as children approach adolescence and seek greater autonomy, but still require support and guidance through challenging peer dynamics. That maternal depression did not mediate the relationship between interparental intimacy and child depression was unexpected. The proximate role of fathers' depression in reducing children's depressive symptoms may be a function of the fathering vulnerability hypothesis [53]. Supporters of this hypothesis argue that fathers may be particularly susceptible to the effects of high marital quality. Specifically, fathers' (but not mothers') self-reported marital happiness has been associated with improved parenting [34]. Father's parenting may be a mechanism for future research to further understand the link between paternal and child depression.

\section{Limitations and conclusions}

The current study includes some limitations worth noting. First, because findings are based on a community sample, not a clinicallydepressed sample, the extent to which these family dynamics impact more severe forms of depression remains unclear. Second, alternative research designs may identify bidirectional effects whereby children's depression impacts the parent-child relationship, marriage, or other key family dynamics. Future studies' use of a narrower time scale and additional assessments may reveal nonlinear, discontinuous patterns of change and bidirectional relations [11]. Recent research using daily diary data, for example, has demonstrated bidirectional associations between parent-adolescent conflict and the adolescent's daily negative mood [54]. Finally, depression is known to be moderately influenced by heritability, but the lack of genetic information in the current study's data precludes examination of heritability estimates [55].

Despite these limitations, the data yield important information about trajectories of depressive symptomatology across development. The findings offer insight into key family processes that may reduce the likelihood of persistent depressive symptoms as children transition into adolescence. By identifying protective factors in depressive symptom trajectories, prevention and intervention efforts may become more targeted and systemic such that the entire family becomes the focus of programmatic change designed to improve children's mental health.

\section{References}

1. Lewinsohn PM, Hops H, Roberts RE, Seeley JR, Andrews JA (1993) Adolescent psychopathology: I. Prevalence and incidence of depression and other DSM-III-R disorders in high school students. J Abnorm Psychol 102: 133-144. [Crossref]

2. Cicchetti D, Toth SL (1998) The development of depression in children and adolescents. Am Psychol 53: 221-241. [Crossref]

3. Kessler R, Walters E (1998) Epidemiology of DSM-III-R major depression and minor depression among adolescents and young adults in the National Comorbidity Survey. Depress Anxiety 7: 3-14. [Crossref]

4. Castelao CF, Kroner-Herwig B (2013) Different trajectories of depressive symptoms in children and adolescents: Predictors and differences in girls and boys. $J$ Youth Adolesc 42: 1169-1182. [Crossref]

5. Dekker MC, Ferdinand RF, van Lang NJ, Bongers IL, van der Ende J, et al. (2007) Developmental trajectories of depressive symptoms from early childhood to late adolescence: gender differences and adult outcome. J Child Psychol Psychiatry 48: 657-666. [Crossref]

6. Diamantopoulou S, Verhulst FC, van der Ende J (2011) Gender differences in the development and adult outcome of co-occurring depression and delinquency in adolescence. J Abnorm Psychol 120: 644-655. [Crossref]

7. Reinke WM, Eddy JM, Dishion TJ, Reid JB (2012) Joint trajectories of disruptive behavior problems and depressive symptoms during early adolescence and adjustment problems during emerging adulthood. J Abnorm Child Psychol 40: 1123-1136. [Crossref]

8. Needles DJ, Abramson LY (1990) Positive life events, attributional style, and hopefulness: Testing a model of recovery from depression. J Abnorm Psychol 99: 156165. [Crossref]

9. Stoolmiller M, Kim HK, Capaldi DM (2005) The course of depressive symptoms in men from early adolescence to young adulthood: Identifying latent trajectories and early predictors. J Abnorm Psychol 114: 331-345. [Crossref] 
10. Costello DM, Swendsen J, Rose JS, Dierker LC (2008) Risk and protective factors associated with trajectories of depressed mood from adolescence to early adulthood. $J$ Consult Clin Psychol 76: 173-183. [Crossref]

11. Sterba SK, Prinstein MJ, Cox MJ (2007) Trajectories of internalizing problems across childhood: Heterogeneity, external validity, and gender differences. Dev Psychopathol 19: 345-366. [Crossref]

12. Frye AA, Liem JH (2011) Diverse patterns in the development of depressive symptoms among emerging adults. Journal of Adolescent Research 26: 570-590.

13. Cornwell B (2003) The dynamic properties of social support: Decay, growth, and staticity, and their effects on adolescent depression. Social Forces 81: 953-978.

14. Formoso D, Gonzales NA, Aiken LS (2000) Family conflict and children's internalizing and externalizing behavior: protective factors. Am J Community Psychol 28: 175-199. [Crossref]

15. Walsh F (2016) Strengthening Family Resilience. NY: The Guilford Press.

16. Jackson AP (1999) The effects of nonresident father involvement on single black mothers and their young children. Soc Work 44: 156-166. [Crossref]

17. McLanahan S (1988) The consequences of single parenthood for subsequent generations. Focus 11: 16-21.

18. Amato PR (2001) Children of divorce in the 1990s: an update of the Amato and Keith (1991) meta-analysis. J Fam Psychol 15: 355-370. [Crossref]

19. Anderson AL (2002) Individual and contextual influences on delinquency: The role of the single-parent family. Journal of Criminal Justice 30: 575-587.

20. Teel KS, Verdeli H, Wickramaratne P, et al. (2016) Impact of a Father Figure's Presence in the Household on Children's Psychiatric Diagnoses and Functioning in Families at High Risk for Depression. J Child Fam Stud 25: 588-597. [Crossref]

21. Grall T (2013) Custodial mothers and fathers and their child support: 2011. Washington, DC.

22. Roy AL, Raver CC (2014) Are all risks equal? Early experiences of poverty-related risk and children's functioning. J Fam Psychol 28: 391-400. [Crossref]

23. Cairney J, Boyle M, Offord DR, Racine Y (2003) Stress, social support and depression in single and married mothers. Soc Psychiatry Psychiatr Epidemiol 38: 442-449. [Crossref]

24. Broderick CB (1993) Understanding family process: Basics of family systems theory. Newbury Park, CA: Sage.

25. Cox MJ, Paley B (1997) Families as systems. Annu Rev Psychol 48: 243-267. [Crossref]

26. Almeida DM, Wethington E, Chandler AL (1999) Daily transmission of tensions between marital dyads and parent-child dyads. Journal of Marriage and the Family 61: 49-61.

27. Cummings EM, Davies PT (1994) Children and marital conflict: The impact of family dispute and resolution. New York: Guilford Press.

28. Low SM, Stocker C (2005) Family functioning and children's adjustment: Associations among parents' depressed mood, marital hostility, parent-child hostility, and children's adjustment. J Fam Psychol 19: 394-403. [Crossref]

29. Du Rocher Schudlich TD, Cummings EM (2007) Parental dysphoria and children's adjustment: marital conflict styles, children's emotional security, and parenting as mediators of risk. J Abnorm Child Psychol 35: 627-639. [Crossref]

30. Harold GT, Conger RD (1997) Marital conflict and adolescent distress: the role of adolescent awareness. Child Dev 68: 333-350. [Crossref]

31. Harold GT, Osborne LN, Conger RD (1997) Mom and dad are at it again: Adolescent perceptions of marital conflict and adolescent psychological distress. Dev Psychol 33: 333-350. [Crossref]

32. Gregson KD, Erath SA, Pettit GS, Tu KM (2016) Are They Listening? Parental Socia Coaching and Parenting Emotional Climate Predict Adolescent Receptivity. $J$ Res Adolesc 26: 738-752. [Crossref]
33. Easterbrooks MA, Cummings E, Emde RN (1994) Young children's response to constructive marital disputes. Journal of Family Psychology 8: 160-169.

34. NICHD Early Child Care Research Network (2000) Factors associated with fathers caregiving activities and sensitivity with young children. Journal of Family Psychology 14: 200-219. [Crossref]

35. Taraban L, Shaw DS, Leve LD, Wilson MN, Dishion TJ, et al. (2017) Materna depression and parenting in early childhood: Contextual influence of marital quality and social support in two samples. Dev Psychol 53: 436-449. [Crossref]

36. Mamun AA1, Clavarino AM, Najman JM, Williams GM, O'Callaghan MJ, et al. (2009) Maternal depression and the quality of marital relationship: a 14-year prospective study. J Womens Health (Larchmt) 18: 2023-2031. [Crossref]

37. Rehman US, Gollan J, Mortimer AR (2008) The marital context of depression: Research, limitations, and new directions. Clin Psychol Rev 28: 179-198. [Crossref]

38. Dix T, Meunier LN (2009) Depressive symptoms and parenting competence: An analysis of 13 regulatory processes. Developmental Review 29: 45-68.

39. Downey G, Coyne JC (1990) Children of depressed parents: an integrative review. Psychol Bull 108: 50-76. [Crossref]

40. Engle JM, McElwain NL (2013) Parental depressive symptoms and marital intimacy a 4.5 years: Joint contributions to mother-child and father-child interaction at 6.5 years. Developmental Psychology 49: 2225-2235.

41. Shaefer MT, Olson DH (1981) Assessing intimacy: The pair inventory. Journal of Marital and Family Therapy 7: 640-653.

42. Pianta R (1992) Student-Teacher Relationship Scale. Charlottesville, VA: University of Virginia.

43. Radloff LS (1997) The CES-D scale: A self report depression scale for research in general population. Applied Psychological Measurement 1: 385-401.

44. Kovacs M (1992) Children's Depression Inventory- Short Form. North Tonawanda, NY: Multi-Health Systems.

45. Muthen LK, Muthen BO (1998-2012) Mplus: Statistical Analysis with Latent Variables User's Guide. Los Angeles, CA: Muthen \& Muthen.

46. Lo Y, Mendell NR, Rubin DB (2001) Testing the number of components in a norma mixture. Biometrika 88: 767-778.

47. Nagin DS (1999) Analyzing developmental trajectories: A semiparametric, groupbased approach. Psychological Methods 4: 139-157.

48. Raftery A (1995) Bayesian model selection in social research. Social Methodology 25 111-164.

49. Stright AD, Bales SS (2003) Coparenting quality: Contributions of child and paren characteristics. Family Relations 52: 232-240.

50. Suh GW, Fabricius WV, Stevenson MM, Parke RD, Cookston JT, et al. (2016) Effect of the interparental relationship on adolescents' emotional security and adjustment: The important role of fathers. Dev Psychol 52: 1666-1678. [Crossref]

51. Fredrickson BL (2001) The role of positive emotions in positive psychology. The broaden-and-build theory of positive emotions. Am Psychol 56: 218-226. [Crossref]

52. Timko C, Cronkite RC, Berg EA, Moos RH (2002) Children of parents with unipolar depression: A comparison of stably remitted, partially remitted, and nonremitted parents and nondepressed controls. Child Psychiatry Hum Dev 32: 165-185. [Crossref]

53. Cummings EM, Merrilees CE, Geroge MW (2010) Fathers, marriages, and families: Revisiting and updating the framework for fathering in family context. In M. E. Lamb (Ed.), The role of the father in child development (5th ed., pp. 154-176). Hoboken, NJ: Wiley.

54. Timmons AC, Margolin G (2015) Family conflict, mood, and adolescents' daily school problems: Moderating roles of internalizing and externalizing symptoms. Child Dev 86: 241-258. [Crossref]

55. Lohoff FW (2010) Overview of the genetics of major depressive disorder. Curr Psychiatry Rep 12: 539-546. [Crossref]

Copyright: (C2018 Buck KA. This is an open-access article distributed under the terms of the Creative Commons Attribution License, which permits unrestricted use, distribution, and reproduction in any medium, provided the original author and source are credited. 